\title{
Sobrevivência de Pseudomonas marginalis pv. marginalis em bulbilhos de alho
}

\author{
Survival of Pseudomonas marginalis pv. marginalis in garlic cloves
}

\author{
Leandro Luiz Marcuzzo*, Dionatan Alan Amler \\ Instituto Federal Catarinense, Rio do Sul, SC, Brasil. * Autor para correspondência: leandro.marcuzzo@ifc.edu.br
}

Submissão: 01/05/2020 / Aceite: 01/07/2020

\begin{abstract}
RESUMO
A queima-bacteriana-do-alho causada por Pseudomonas marginalis pv. marginalis é uma das principais doenças foliares da cultura e pouco se conhece de sua dinâmica de sobrevivência no bulbilho. Dentro deste aspecto, o objetivo deste trabalho foi avaliar a sobrevivência desta bactéria no bulbilho com e sem assepsia durante o armazenamento. Bulbilhos de alho do cultivar Chonan foram inoculados com isolado mutante a rifampicina de $P$. marginalis pv. marginalis para diferenciar de outras bactérias e foram transplantados a campo. Ao final do ciclo da cultura foi avaliada a população presente no bulbilho e mensalmente até o sexto mês de armazenamento. Para quantificação da população bacteriana foram realizadas três repetições composta de dez gramas cada de bulbilhos sem e com assepsia com hipoclorito de sódio por três minutos, seguida do isolamento pela técnica de diluição seriada seguida de plaqueamento em meio de cultura King-B com rifampicina para isolamento seletivo da bactéria. Após incubação de 48 horas a $28{ }^{\circ} \mathrm{C}$, as colônias foram contadas para analisar mensalmente a sua sobrevivência no bulbilho. Mediante aos resultados obtidos, a bactéria não tem capacidade de sobreviver nos bulbilhos submetidos à assepsia durante o armazenamento, mas consegue sobreviver sem assepsia por até três meses.
\end{abstract}

PALAVRAS-CHAVE: Allium sativum, bactéria, epidemiologia.

\begin{abstract}
Bacterial soft rot of garlic caused by Pseudomonas marginalis pv. marginalis is one of the crop's main leaf diseases, and little is known about its dynamics of survival in the clove. Accordingly, this study set out to determine this bacterium's survival in the clove with and without asepsis during storage. Garlic cloves of the Chonan cultivar were inoculated with an isolated rifampicin-resistant mutant of $P$. marginalis pv. marginalis to distinguish them from other bacteria and were transplanted in the field. The population present in the clove was evaluated at the end of the crop cycle and then on a monthly basis until the sixth month in storage. To quantify the bacterial population, three replications were conducted with ten grams each of cloves with and without asepsis by sodium hypochlorite for three minutes. Serial dilution was then used for isolation, followed by plating in a King B culture medium with rifampicin for selective isolation of the bacterium. After 48 hours of incubation at $28{ }^{\circ} \mathrm{C}$, the colonies were counted on a monthly basis to analyze their survival in the clove. The results indicate that the bacterium is unable to survive in cloves subjected to asepsis during storage, but it can survive without asepsis for up to three months.
\end{abstract}

KEYWORDS: Allium sativum, bacteria, epidemiology.

A queima-bacteriana-do-alho (Allium sativum L.) causada por Pseudomonas marginalis pv. marginalis (Brown) Stevens (sin. P. fluorescens biovar II) é a mais importante bacteriose foliar na cultura em todo Brasil (BECKER 2004). Os sintomas podem se manifestar em qualquer estádio de desenvolvimento da planta, onde inicialmente as folhas apresentam uma descoloração parcial ou total e posteriormente a formação de estrias amareladas alongadas e com a evolução da doença, ocorre um encharcamento de cor marrom e amolecimento na nervura central (CALZOLARI \& BAZZI 1985, SOUZA 2009, MARCUZZO 2018). O restante do limbo pode permanecer verde e firme, porém, tende a ocupar todo o limbo foliar apresentando, ao final, uma coloração marrom e ressequida com aspecto de maturação fisiológica da planta (BECKER 1991). Os sintomas podem progredir para o pseudocaule e bulbo podendo ocorrer o seu apodrecimento (LOPES \& QUEZADO-SOARES 1997). Entres as características dessa bactéria é a emissão de fluorescência em luz 
negra quando cultivada em meio de cultura King-B (ROMEIRO 1995, MOURA \& ROMEIRO 1997).

A doença disseminou por todo o Brasil, principalmente na região do cerrado onde não havia a cultura. Segundo BECKER (2004) e LUCINI (2004) descrevem que os bulbilhos contaminados é o responsável por introduzir essa doença em novas áreas, no entanto, BATISTA et al. (1989) alega que a bactéria não sobrevive nos bulbilhos após seis meses de armazenamento, mas sem detalhes adicionais durante esse período.

Mediante a isso, esse trabalho tem como objetivo avaliar a sobrevivência da bactéria nos bulbilhos durante período de armazenamento do alho.

O trabalho foi conduzido no Instituto Federal Catarinense - IFC/Campus Rio do Sul, no município de Rio do Sul, SC, (Latitude: 27ำ1'07" S e Longitude: 4939'39" W, altitude 655 metros acima do nível do mar) durante o período de armazenamento em galpão convencional coberto e ventilado lateralmente de novembro de 2019 a maio de 2020 , totalizando seis meses após a colheita.

Foi utilizado isolado de $P$. marginalis pv. marginalis isolado de folhas de alho e mutante a rifampicina $\left(\mathrm{Pmm}^{\text {rf }}\right)$ obtida de colônia isolada em meio de cultura King-B contendo rifampicina $150 \mathrm{mg} / \mathrm{L}$ e plaqueada por três vezes consecutivas para manutenção da resistência a rifampicina. A finalidade da bactéria mutante é ser diferenciadora de outras bactérias florescentes que não são isoladas devido o meio ser específico para esta.

Bulbilhos de alho do cv. Chonan foram microbiolizados por 5,5 horas (MARCUZZO 2002) em uma suspensão de $\mathrm{Pmm}^{\text {rf }} \mathrm{com} 48$ horas de crescimento preparada em solução salina $(\mathrm{NaCl} 0,85 \%)$, a uma

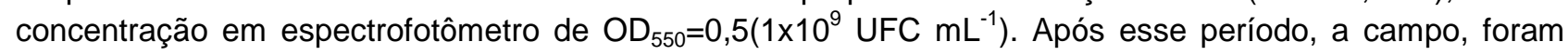
semeadas em quatro canteiros contendo cada um 5 metros de comprimento por 1,25 m de largura. Em cada canteiro com cinco linhas foram semeados 250 bulbilhos, com espaçamento de 0,25 entre filas e 0,10 entre plantas. A calagem, adubação de plantio e de cobertura e os tratos culturais foram feitos conforme recomendação para a cultura (NICK \& BORÉM 2017). Para os tratamentos fitossanitários, visando ao

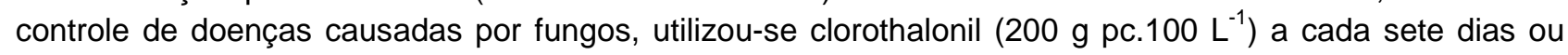
após a precipitação acumulada de $25 \mathrm{~mm}$. O clorotalonil não apresenta interferência sobre a bactéria em estudo (MARCUZZO 1999).

No momento da colheita foram coletados dez bulbos e também a cada um mês de armazenamento para quantificação da bactéria no bulbilho. A avaliação da população de $\mathrm{Pmm}^{\text {rf }}$ no bulbilho, foi feita em três repetições contendo sub-amostra de 10 gramas de bulbilhos com assepsia por três minutos em solução de hipoclorito de sódio a 1,25\%, onde em seguida foram lavadas com água destilada estéril e trituradas em liquidificador por um minuto contendo $100 \mathrm{ml}$ de solução salina ( $\mathrm{NaCl}$ 0,85\%). Um tratamento sem assepsia seguiu os mesmos procedimentos. Uma alícota de $1 \mathrm{ml}$ da solução foi transferida para tubo contendo solução salina e agitadas com auxílio de um agitador de tubos durante cinco segundos e, em seguida, foi diluída em série até $10^{-5}$ e plaqueada com auxílio de alça de Drigalski em meio de cultura King-B, acrescida de rifampicina a $150 \mathrm{mg} \mathrm{L}^{-1}$ e uma suspensão de $100 \mu \mathrm{l}$ de Clorotalonil $\left(1,3 \mathrm{~g} \mathrm{~L}^{-1}\right)$ espalhada em sua superfície para não ocorrer a proliferação de fungos. Após a incubação em estufa tipo B.O.D (Biological Demand Oxigen) com temperatura de $28^{\circ} \mathrm{C}$ por 48 horas, as colônias de Pmm ${ }^{\text {tf }}$ foram contadas em câmara de luz negra para a observação da fluorescência emitida pela bactéria mutante isolada dos bulbilhos com e sem assepsia e expressa em UFC (unidade formadora de colônia).

Mediante aos resultados obtidos, constatou-se que a população de bactéria quando submetida a assepsia superficial do bulbilho extinguiu a sua população já no primeiro mês de armazenamento, evidenciando que a bactéria não sobrevive dentro do bulbilho e sim fora deste, como verificado no tratamento sem assepsia (Tabela 1). Entre as hipóteses da bactéria não sobreviver dentro do bulbilho é devido aos compostos químicos do alho como a alicina (dialil-tiosulfinato) que tem efeito bactericida (FONSECA et al. 2014, FERREIRA et al. 2016).

A característica da bactéria estar externamente ao bulbilho por até três meses é que as bactérias tem a fase epifítica em seu ciclo de vida (ROMEIRO 1995). Nessa fase a bactéria acaba sobrevivendo à custa de exsudados provenientes da planta ou das túnicas e com isso acaba formando um biofilme sobre o bulbilho, o que the garante sua sobrevivência durante esse período de armazenamento (MARCUZZO 2009). Quando esse bulbilho é semeado a campo a bactéria penetra pelos estômatos das folhas primárias e iniciase o processo epidêmico da doença na cultura (BEATTIE \& LINDOW 1995, MARCUZZO \& DENARDIN 2008). Os resultados estão de acordo com BATISTA et al. (1989), pois eles não encontram a bactéria após seis meses de armazenamento e alegaram que as bactérias por estarem localizadas nas túnicas externas, não sobrevivem a sua dessecação. 
Tabela 1. População de Pseudomonas marginalis pv. marginalis em bulbilhos de alho cv. Chonan com e sem assepsia na colheita e durante o armazenamento. IFC/Campus Rio do Sul 2019-2020.

Table 1. Population of Pseudomonas marginalis pv. marginalis in garlic cloves of the Chonan cultivar with and without asepsis at harvest and during storage. IFC/Campus Rio do Sul 2019-2020.

\begin{tabular}{|c|c|c|}
\hline \multirow[t]{2}{*}{ Período } & \multicolumn{2}{|c|}{ População bacteriana (UFC/10 gramas de bulbilho) } \\
\hline & Sem assepsia & Com assepsia \\
\hline Colheita & $1,23 \times 10^{5}$ & $5,00 \times 10^{4}$ \\
\hline $1^{\circ}$ mês de armazenamento & $1,67 \times 10^{4}$ & 0 \\
\hline $2^{\circ}$ - mês de armazenamento & $3,33 \times 10^{3}$ & 0 \\
\hline 3ํ mês de armazenamento & $6,67 \times 10^{1}$ & 0 \\
\hline $4^{\circ}$ mês de armazenamento & 0 & 0 \\
\hline $5^{\circ}$ mês de armazenamento & 0 & 0 \\
\hline 6을 de armazenamento & 0 & 0 \\
\hline
\end{tabular}

O período de sobrevivência da bactéria nos bulbilhos sem assepsia foi representado pela equação polinomial $y=15907 x^{2}-12170 x+21875$ com um coeficiente de determinação altamente significativo de $92 \%$, do qual reduziu de uma população de $1,67 \times 10^{4}$ para $6,67 \times 10^{1}$ UFC/10 gramas de bulbilhos no terceiro mês. Em relação aos bulbilhos submetidos à assepsia seguiu uma linear exata $(R=1)$ expressa em $y=-50000 x+10000$, já que só foi constatada durante a colheita (Figura 1).

Neste trabalho comprova o descrito por LUCINI (2004), em que a doença se proliferou no cerrado devido ao bulbilho contaminado. Isso é condizente, porque o plantio no cerrado começa em fevereiro com 20 a $50 \%$ de bulbilhos sementes vindo do sul do Brasil que é colhido em novembro/dezembro e que tem a população bacteriana (Tabela 1 e Figura 1) presente no bulbilho para iniciar a epidemia da doença na lavoura. No entanto, aqui no sul do Brasil como o plantio inicia na maioria em junho, após seis meses de armazenamento, a bactéria não tem capacidade de sobreviver no bulbilho, confirmando com os resultados encontrados por BATISTA et al. (1989).

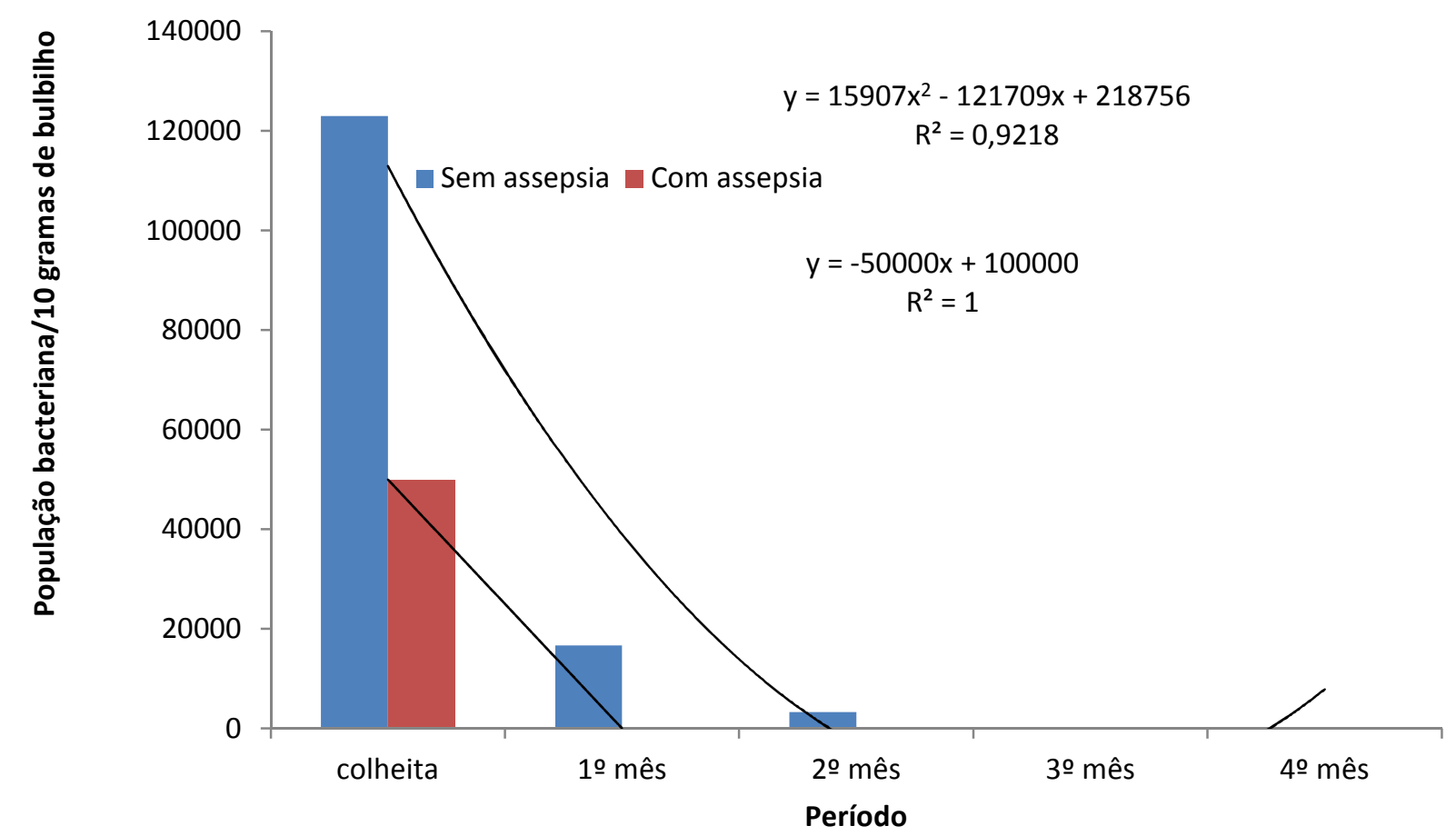

Figura 1. Regressão da população de Pseudomonas marginalis pv. marginalis em bulbilhos de alho cv. Chonan com e sem assepsia na colheita e durante o armazenamento. IFC/Campus Rio do Sul 2019-2020.

Figure 1. Regression of the population of Pseudomonas marginalis pv. marginalis in garlic cloves of the Chonan cultivar with and without asepsis at harvest and during storage. IFC/Campus Rio do Sul 2019-2020. 
Em função disso uma medida simples e barata é fazer antes no plantio a imersão dos bulbilhos em solução de hipoclorito de sódio 1,25\% por três minutos, seguida de lavagem com água com a finalidade de eliminar essa população externa e não gerar o processo de infecção nas folhas primárias e a consequente epidemia que ocorrerá dentro da lavoura. Resultado oposto foi encontrado por MARINGONI \& KIMOTO (2016) quando imergiram bulbilhos por 30 minutos em solução $\left(2 \mathrm{~g} \mathrm{~L}^{-1}\right)$ de acetato cúprico e de oxitetraciclina, mas sem caracterizar a população bacteriana no bulbilho e o tempo de armazenamento.

Mediante aos resultados, a bactéria tem capacidade de sobreviver externamente ao bulbilho durante três meses de armazenamento, mas não quando submetida à assepsia em solução de hipoclorito de sódio $1,25 \%$ por três minutos.

\section{REFERÊNCIAS}

BATISTA MG et al. 1989. Sobrevivência de Pseudomonas fluorescens, Biovar Il em bulbilhos de alho e sobrevivência a diferentes hospedeiros. Fitopatologia Brasileira 14:121.

BEATTIE GA \& LINDOW SE. 1995. The secret life of foliar bacterial pathogens on leaves. Annual Review of Phytopathology 33: 145-172.

BECKER WF. 1991. Queima bacteriana do alho. Agropecuária Catarinense 4: 14-19.

BECKER WF. 2004. Doenças do alho: sintomatologia e controle. Florianópolis: Epagri. 53p.

CALZOLARI A \& BAZZI O. 1985. Um marciume fogliare Dell"alio causato da Pseudomonas fluorescens. Informatore Fitopatológico 7-8: 35-38.

FERREIRA et al. 2016. Eficiência da ação antimicrobiana do óleo essencial de alho (Allium sativum). Sinapse Múltipla 5: 102.

FONSECA GM et al. 2014. Avaliação da atividade antimicrobiana do alho (Allium sativum Liliaceae) e de seu extrato aquoso. Revista Brasileira de Plantas Medicinais 16: 679-684.

LOPES CA \& QUEZADO-SOARES AM. 1997. Doenças bacterianas das hortaliças: Diagnose e controle. Brasília: EMBRAPA. 70p.

LUCINI MA. 2004. Alho: manual prático de produção. Curitibanos: Bayer Crop Science. 140p.

MARCUZZO LL. 2018. Queima bacteriana em alho. Cultivar Hortaliças e Frutas 112: 5-7.

MARCUZZO LL. 2009. Importância das populações epifíticas na epidemiologia de enfermidades bacterianas. Revista de Ciências Agroveterinárias 8: 146-151.

MARCUZZO LL. 2002. Seleção e caracterização biológica de bactérias com potencial para o controle biológico da queima bacteriana do alho. Dissertação (Mestrado em Fitossanidade). Pelotas: UFPel. 52p.

MARCUZZO LL. 1999. Fitopatologia - Avaliação da Sensibilidade in vitro da Pseudomonas fluorescens (queima bacteriana), biovar II à bactericidas. Monografia (Graduação em Agronomia). Lages: UDESC. 57p.

MARCUZZO LL \& DENARDIM ND. 2008. Colonização de bactérias causadoras de doenças foliares. Revista de Ciências Agroveterinárias 7: 169-176.

MARINGONI AC \& KIMOTO T. 2016. Efeito do tratamento de bulbilhos de alho com bactericidas na ocorrência da estria bacteriana, no desenvolvimento e na produção das plantas. Scientia Agraria Paranaensis 15: 175-177.

MOURA AB \& ROMEIRO RS. 1997. Garlic bulbils as biological baits for detection an diagnosis of Pseudomonas marginalis. Summa Phytopathologica 23: 252-254.

NICK C \& BORÉM A. 2017. Alho: do plantio a colheita. Viçosa: UFV. 173p.

ROMEIRO RS. 1995. Doenças causadas por bactérias em alho. Informe Agropecuário 17: 46-49.

SOUZA PE. 2009. Doenças do alho. In: SOUZA RJ \& MACEDO FS. (Ed.). Cultura do alho: tecnologias modernas de produção. Lavras: UFLA. p.109-126. 